\begin{tabular}{|c|c}
\hline Caucasian Journal of Science & $\begin{array}{c}\text { ISSN: } 2148-6840 \\
\text { https://doi.org/10.48138/cjo.1028755 }\end{array}$ \\
\hline
\end{tabular}

\title{
Neighborhoods of Certain Classes of Analytic Functions Defined By Miller-Ross Function
}

\section{Sercan KAZIMOĞLU1}

\begin{tabular}{|c|c|}
\hline Makale Bilgileri & Özet \\
\hline Geliş Tarihi & Bu makalede, normalize edilmiş Miller-Ross yardımıyla tanımlanan negatif katsayılı açık \\
\hline 26.11.2021 & $\begin{array}{l}\text { U birim diskinde analitik fonksiyonların yeni bir alt sınıfını tanıtacağız. Bu makalenin } \\
\text { amacı, tanıtılan bu alt sınıfa ait Miller-Ross fonksiyonu için katsayı eşitsizliklerini, }\end{array}$ \\
\hline Kabul Tarihi & indirgeme bağıntılarını ve komşuluk özelliklerini belirlemektir. \\
\hline 28.12 .2021 & \\
\hline \multicolumn{2}{|l|}{ Anahtar Kelimeler } \\
\hline \multicolumn{2}{|l|}{ Analitik Fonksiyon } \\
\hline \multicolumn{2}{|l|}{ Yıldızıl ve Konveks } \\
\hline \multicolumn{2}{|l|}{ Fonksiyonlar } \\
\hline \multicolumn{2}{|l|}{ Miller-Ross } \\
\hline \multicolumn{2}{|l|}{ Fonksiyonu } \\
\hline Komşuluklar & \\
\hline
\end{tabular}

\begin{tabular}{ll}
\hline Article Info & Abstract \\
\hline $\begin{array}{l}\text { Received } \\
26.11 .2021\end{array}$ & $\begin{array}{l}\text { In this paper, we introduce a new subclass of analytic functions in the open unit disk U } \\
\text { with negative coefficients defined by normalized of the Miller-Ross function. The object } \\
\text { of the present paper is to determine coefficient inequalities, inclusion relations and } \\
\text { neighborhoods properties for Miller-Ross function belonging to this subclass. }\end{array}$ \\
$\begin{array}{l}\text { Accepted } \\
28.12 .2021\end{array}$ & \\
\hline $\begin{array}{l}\text { Keywords } \\
\text { Analytic Function } \\
\text { Starlike and } \\
\text { Convex Functions } \\
\text { Miller-Ross }\end{array}$ \\
Function \\
Neighborhoods
\end{tabular}

\section{Introduction}

Let $\mathrm{A}$ be a class of functions $f$ of the form

$$
f(z)=z+\sum_{n=2}^{\infty} a_{n} z^{n}
$$

that are analytic in the open disk $\mathrm{U}=\{z:|z|<1\}$. Denote by $\mathrm{A}(n)$ the class of functions consisting of functions $f$ of the form

$$
f(z)=z-\sum_{n=2}^{\infty} a_{n} z^{n}, \quad\left(a_{n} \geq 0\right)
$$

which are analytic in U..

${ }^{1}$ Kafkas University Faculty of Science and Letters Department of Mathematics-Kars; e-mail: srcnkzmglu@gmail.com; ORCID: 0000-0002$1023-4500$ 
We recall that the convolution (or Hadamard product) of two functions

$$
f(z)=z+\sum_{n=2}^{\infty} a_{n} z^{n} \text { and } g(z)=z+\sum_{n=2}^{\infty} b_{n} z^{n}
$$

is given by

$$
(f * g)(z):=z+\sum_{n=2}^{\infty} a_{n} b_{n} z^{n}=:(g * f)(z), \quad(z \in \mathrm{U}) .
$$

Note that $f * g \in \mathrm{A}$.

Next, following the earlier investigations by (Goodman, 1957), (Ruscheweyh, 1981), (Silverman, 1995), (Altıntaş \& Owa, 1996; Altıntaş et al., 2000) and (Srivastava \& Bulut, 2012) (see also Aktaş \& Orhan, 2015; Çağlar \& Orhan, 2017; Çağlar \& Orhan, 2019; Çağlar et al., 2020; Darwish et al., 2015; Deniz \& Orhan, 2010; Keerthi et al., 2008; Murugusundaramoorthy \& Srivastava, 2004; Orhan, 2007), we define the $(n, \delta)$ - neighborhood of a function $f \in \mathrm{A}(n)$ by

$$
\mathrm{N}_{n, \delta}(f)=\left\{g \in \mathrm{A}(n): g(z)=z-\sum_{n=2}^{\infty} b_{n} z^{n} \text { and } \sum_{n=2}^{\infty} n\left|a_{n}-b_{n}\right| \leq \delta\right\} \text {. }
$$

For $e(z)=z$, we have

$$
\mathrm{N}_{n, \delta}(e)=\left\{g \in \mathrm{A}(n): g(z)=z-\sum_{n=2}^{\infty} b_{n} z^{n} \text { and } \sum_{n=2}^{\infty} n\left|b_{n}\right| \leq \delta\right\} .
$$

A function $f \in \mathrm{A}(n)$ is $\alpha$-starlike of complex order $\gamma$, denoted by $f \in \mathrm{S}_{n}^{*}(\alpha, \gamma)$ if it satisfies the following condition

$$
\mathfrak{R}\left\{1+\frac{1}{\gamma}\left(\frac{z f^{\prime}(z)}{f(z)}-1\right)\right\}>\alpha, \quad(\gamma \in \square \backslash\{0\}, 0 \leq \alpha<1, z \in \mathrm{U})
$$

and a function $f \in \mathrm{A}(n)$ is $\alpha$-convex of complex order $\gamma$, denoted by $f \in \mathrm{C}_{n}^{*}(\alpha, \gamma)$ if it satisfies the following condition

$$
\mathfrak{R}\left\{1+\frac{1}{\gamma} \frac{z f^{\prime \prime}(z)}{f^{\prime}(z)}\right\}>\alpha, \quad(\gamma \in \square \backslash\{0\}, 0 \leq \alpha<1, z \in \mathrm{U}) .
$$

The Miller-Ross (Miller \& Ross, 1993) function $E_{v, c}(z)$, defined by

$$
E_{v, c}(z)=z^{v} \sum_{n=0}^{\infty} \frac{c^{n}}{\Gamma(v+n+1)} z^{n(1+\alpha)}, \quad(v>-1, c \geq 0, z \in \mathrm{U}) .
$$

The Miller-Ross function $E_{v, c}(z)$ does not belong to the class $\mathrm{A}$. Therefore, we consider the following normalization for the function $E_{v, c}(z)$ :

$$
\mathrm{E}_{v, c}(z)=\Gamma(1+v) z^{1-v} E_{v, c}(z)=\sum_{n=0}^{\infty} \frac{c^{n} \Gamma(1+v)}{\Gamma(v+n+1)} z^{n+1}, \quad(z \in \mathrm{U}) .
$$

In terms of Hadamard product and $\mathrm{E}_{v, c}(z)$ given by (1.6), a new operator $\varepsilon_{v, c}: \mathrm{A} \rightarrow \mathrm{A}$ can be defined as follows: 


$$
\varepsilon_{v, c} f(z)=\left(\varepsilon_{v, c} * f\right)(z)=z+\sum_{n=1}^{\infty} \frac{c^{n} \Gamma(1+v) a_{n+1}}{\Gamma(v+n+1)} z^{n+1}, \quad(z \in \mathrm{U}) .
$$

If $f \in \mathrm{A}(n)$ is given by (1.2), then we have

$$
\varepsilon_{v, c} f(z)=z-\sum_{n=1}^{\infty} \frac{c^{n} \Gamma(1+v) a_{n+1}}{\Gamma(v+n+1)} z^{n+1}, \quad(z \in \mathrm{U}) .
$$

Finally, by using the differential operator defined by (1.8), we investigate the subclasses $\mathrm{M}_{v, c}^{n}(\alpha, \gamma)$ and $\mathrm{R}_{v, c}^{n}(\alpha, \gamma ; \vartheta)$ of $\mathrm{A}(n)$ consisting of functions $f$ as the followings:

However, throughout this paper, we restrict our attention to the case real-valued $v, c$ with $v>-1$ and $c \geq 0$.

Definition 1.1: The subclass $\mathrm{M}_{v, c}^{n}(\alpha, \gamma)$ of $\mathrm{A}(n)$ is defined as the class of functions $f$ such that

$$
\left|\frac{1}{\gamma}\left(\frac{z\left[\varepsilon_{v, c} f(z)\right]^{\prime}}{\varepsilon_{v, c} f(z)}-1\right)\right|<\alpha, \quad(z \in \mathrm{U}),
$$

where $\gamma \in \square \backslash\{0\}$ and $0 \leq \alpha<1$.

Definition 1.2: Let $\mathrm{R}_{v, c}^{n}(\alpha, \gamma ; \vartheta)$ denote the subclass of $\mathrm{A}(n)$ consisting of $f$ which satisfy the inequality

$$
\left|\frac{1}{\gamma}[(1-\vartheta)] \frac{\varepsilon_{v, c} f(z)}{z}+\vartheta\left(\varepsilon_{v, c} f(z)\right)^{\prime}-1\right|<\alpha,
$$

where $\gamma \in \square \backslash\{0\}, 0 \leq \alpha<1$ and $0 \leq \vartheta \leq 1$.

In this paper, we obtain the coefficient inequalities, inclusion relations and neighborhood properties of the subclasses $\mathrm{M}_{v, c}^{n}(\alpha, \gamma)$ and $\mathrm{R}_{v, c}^{n}(\alpha, \gamma ; \vartheta)$.

2. Coefficient Inequalities For $\mathrm{M}_{v, c}^{n}(\alpha, \gamma)$ and $\mathrm{R}_{v, c}^{n}(\alpha, \gamma ; \vartheta)$.

Theorem 2.1: Let $f \in \mathrm{A}(n)$. Then $f \in \mathrm{M}_{v, c}^{n}(\alpha, \gamma)$ if and only if

$$
\sum_{n=2}^{\infty} \frac{c^{n-1} \Gamma(1+v)}{\Gamma(v+n)}[n-1+\alpha|\gamma|] a_{n} \leq \alpha|\gamma| \quad(z \in \mathrm{U})
$$

for $\gamma \in \square \backslash\{0\}$ and $0 \leq \alpha<1$.

Proof. Let $f \in \mathrm{A}(n)$. Then, by (1.9) we can write

$$
\mathfrak{R}\left\{\frac{z\left[\varepsilon_{v, c} f(z)\right]^{\prime}}{\varepsilon_{v, c} f(z)}-1\right\}>-\alpha|\gamma|, \quad(z \in \mathrm{U}) .
$$


Using (1.2) and (1.8), we have,

$$
\mathfrak{R}\left\{\frac{-\sum_{n=2}^{\infty} \frac{c^{n-1} \Gamma(1+v)}{\Gamma(v+n)}[n-1] a_{n} z^{n}}{z-\sum_{n=2}^{\infty} \frac{c^{n-1} \Gamma(1+v)}{\Gamma(v+n)} a_{n} z^{n}}\right\}>-\alpha|\gamma|, \quad(z \in \mathrm{U}) .
$$

Since (2.3) is true for all $z \in \mathrm{U}$, choose values of $z$ on the real axis. Letting $z \rightarrow 1$, through the real values, the inequality (2.3) yields the desired inequality

$$
\sum_{n=2}^{\infty} \frac{c^{n-1} \Gamma(1+v)}{\Gamma(v+n)}[n-1+\alpha|\gamma|] a_{n} \leq \alpha|\gamma| .
$$

Conversely, supposed that the inequality (2.1) holds true and $|z|=1$, then we obtain

$$
\begin{aligned}
\left|\frac{z\left[\varepsilon_{v, c} f(z)\right]^{\prime}}{\varepsilon_{v, c} f(z)}-1\right| & \leq\left|\frac{\sum_{n=2}^{\infty} \frac{c^{n-1} \Gamma(1+v)}{\Gamma(v+n)}[n-1] a_{n} z^{n}}{z-\sum_{n=2}^{\infty} \frac{c^{n-1} \Gamma(1+v)}{\Gamma(v+n)} a_{n} z^{n}}\right| \\
& \leq \frac{\sum_{n=2}^{\infty} \frac{c^{n-1} \Gamma(1+v)}{\Gamma(v+n)}[n-1] a_{n}}{1-\sum_{n=2}^{\infty} \frac{c^{n-1} \Gamma(1+v)}{\Gamma(v+n)} a_{n}} \\
& \leq \alpha|\gamma| .
\end{aligned}
$$

Hence, by the maximum modulus theorem, we have $f(z) \in \mathbf{M}_{v, c}^{n}(\alpha, \gamma)$, which establishes the required result.

Theorem 2.2: Let $f \in \mathrm{A}(n)$. Then $f \in \mathrm{R}_{v, c}^{n}(\alpha, \gamma ; \vartheta)$ if and only if

$$
\sum_{n=2}^{\infty} \frac{c^{n-1} \Gamma(1+v)}{\Gamma(v+n)}[1+\vartheta(n-1)] a_{n} \leq \alpha|\gamma|
$$

for $\gamma \in \square \backslash\{0\}, 0 \leq \alpha<1$ and $0 \leq \vartheta \leq 1$.

Proof. We omit the proofs since it is similar to Theorem 2.1.

3. Inclusion Relations Involving $\mathrm{N}_{n, \delta}(e)$ of $\mathrm{M}_{\nu, c}^{n}(\alpha, \gamma)$ and $\mathrm{R}_{v, c}^{n}(\alpha, \gamma ; \vartheta)$

Theorem 3.1: If

$$
\delta=\frac{2 \alpha|\gamma|(1+v)}{c(1+\alpha|\gamma|)}, \quad(|\gamma|<1)
$$

then $\mathrm{M}_{v, c}^{n}(\alpha, \gamma) \subset \mathrm{N}_{n, \delta}(e)$.

Proof. Let $f(z) \in \mathbf{M}_{v, c}^{n}(\alpha, \gamma)$. By Theorem 2.1, we have 


$$
\frac{c}{(1+v)}(1+\alpha|\gamma|) \sum_{n=2}^{\infty} a_{n} \leq \alpha|\gamma|
$$

which implies

$$
\sum_{n=2}^{\infty} a_{n} \leq \frac{\alpha|\gamma|}{\frac{c}{(1+v)}(1+\alpha|\gamma|)}
$$

Using (2.1) and (3.2), we get

$$
\begin{aligned}
\frac{c}{(1+v)} \sum_{n=2}^{\infty} n a_{n} & \leq \alpha|\gamma|+\frac{c}{(1+v)}(1-\alpha|\gamma|) \sum_{n=2}^{\infty} a_{n} \\
& \leq \frac{2 \alpha|\gamma|}{(1+\alpha|\gamma|)}=\delta .
\end{aligned}
$$

That is,

$$
\sum_{n=2}^{\infty} n a_{n} \leq \frac{2 \alpha|\gamma|}{\frac{c}{(1+v)}(1+\alpha|\gamma|)}=\delta .
$$

Thus, by the definition given by (1.4), $f(z) \in \mathrm{N}_{n, \delta}(e)$, which completes the proof.

Theorem 3.2: If

$$
\delta=\frac{2 \alpha|\gamma|(1+v)}{c(1+\vartheta)}, \quad(|\gamma|<1),
$$

then $\mathrm{R}_{v, c}^{n}(\alpha, \gamma ; \vartheta) \subset \mathrm{N}_{n, \delta}(e)$.

Proof. For $f(z) \in \mathrm{R}_{v, c}^{n}(\alpha, \gamma ; \vartheta)$ and making use of the condition (2.4), we obtain

$$
\frac{c}{(1+v)}(1+\vartheta) \sum_{n=2}^{\infty} a_{n} \leq \alpha|\gamma|
$$

so that

$$
\sum_{n=2}^{\infty} a_{n} \leq \frac{\alpha|\gamma|}{\frac{c}{(1+v)}(1+\vartheta)}
$$

Thus, using (2.4) along with (3.4), we also get

$$
\begin{aligned}
\vartheta \frac{c}{(1+v)} \sum_{n=2}^{\infty} n a_{n} & \leq \alpha|\gamma|+(\vartheta-1) \frac{c}{(1+v)} \sum_{n=2}^{\infty} a_{n} \\
& \leq \alpha|\gamma|+\frac{c(\vartheta-1)}{(1+v)} \frac{\alpha|\gamma|(1+v)}{c(1+\vartheta)} \\
& \leq \frac{2 \vartheta \alpha|\gamma|}{(1+\vartheta)}=\delta
\end{aligned}
$$

Hence, 


$$
\sum_{n=2}^{\infty} n a_{n} \leq \frac{2 \alpha|\gamma|}{\frac{c}{(1+v)}(1+\vartheta)}=\delta
$$

which in view of (1.4), completes the proof of theorem.

\section{Neighborhood Properties For The Classes $\mathrm{M}_{v, c}^{n}(\alpha, \gamma, \eta)$ and $\mathrm{R}_{v, c}^{n}(\alpha, \gamma, \eta ; \vartheta)$}

Definition 4.1: For $0 \leq \eta<1$ and $z \in \mathrm{U}$, A function $f(z) \in \mathrm{A}(n)$ is said to be in the class $\mathbf{M}_{v, c}^{n}(\alpha, \gamma, \eta)$ if there exists a function $g(z) \in \mathbf{M}_{v, c}^{n}(\alpha, \gamma)$ such that

$$
\left|\frac{f(z)}{g(z)}-1\right|<1-\eta \text {. }
$$

Analogously, for $0 \leq \eta<1$ and $z \in \mathrm{U}$, A function $f(z) \in \mathrm{A}(n)$ is said to be in the class $\mathrm{R}_{v, c}^{n}(\alpha, \gamma, \eta ; \vartheta)$ if there exists a function $g(z) \in \mathrm{R}_{v, c}^{n}(\alpha, \gamma ; \vartheta)$ such that the inequality (4.1) holds true.

Theorem 4.1: If $g(z) \in \mathrm{M}_{v, c}^{n}(\alpha, \gamma)$ and

$$
\eta=1-\frac{\delta c(1+\alpha|\gamma|)}{2[c(1+\alpha|\gamma|)-\alpha|\gamma|(1+v)]}
$$

then $\mathrm{N}_{n, \delta}(g) \subset \mathrm{M}_{v, c}^{n}(\alpha, \gamma, \eta)$.

Proof. Let $f(z) \in \mathrm{N}_{n, \delta}(g)$. Then,

$$
\sum_{n=2}^{\infty} n\left|a_{n}-b_{n}\right| \leq \delta
$$

which yields the coefficient inequality,

$$
\sum_{n=2}^{\infty}\left|a_{n}-b_{n}\right| \leq \frac{\delta}{2}, \quad(n \in \square) .
$$

Since $g(z) \in \mathrm{M}_{v, c}^{n}(\alpha, \gamma)$ by (3.2), we have

$$
\sum_{n=2}^{\infty} b_{n} \leq \frac{\alpha|\gamma|}{\frac{c}{(1+v)}(1+\alpha|\gamma|)},
$$

and so 


$$
\begin{aligned}
\left|\frac{f(z)}{g(z)}-1\right| & <\frac{\sum_{n=2}^{\infty}\left|a_{n}-b_{n}\right|}{1-\sum_{n=2}^{\infty} b_{n}} \\
& \leq \frac{\delta}{2} \frac{\frac{c}{(1+v)}(1+\alpha|\gamma|)}{(1+v)}(1+\alpha|\gamma|)-\alpha|\gamma| \\
& =1-\eta .
\end{aligned}
$$

Thus, by the definition, $f(z) \in \mathrm{M}_{v, c}^{n}(\alpha, \gamma, \eta)$ for $\eta$ given by (4.2), which establishes the desired result.

Theorem 4.2: If $g(z) \in \mathrm{R}_{v, c}^{n}(\alpha, \gamma ; \vartheta)$ and

$$
\eta=1-\frac{\delta c(1+\vartheta)}{2[c(1+\vartheta)-\kappa|\gamma|(1+v)]},
$$

then $\mathrm{N}_{n, \delta}(g) \subset \mathrm{R}_{v, c}^{n}(\alpha, \gamma, \eta ; \vartheta)$.

Proof. We omit the proofs since it is similar to Theorem 4.1.

\section{REFERENCES}

Aktaş, i., \& Orhan, H. (2015). Distortion bounds for a new subclass of analytic functions and their partial sums. Bulletin of the Transilvania University of Brasov. Mathematics, Informatics, Physics, Series III, 8(2), 1-12.

Altıntaş, O., \& Owa, S. (1996). Neighborhoods of certain analytic functions with negative coefficients. Int. J. Math. and Math. Sci., 19, 797-800.

Altıntaş, O., Özkan, E., \& Srivastava, H. M. (2000). Neighborhoods of a class of analytic functions with negative coefficients. Appl. Math. Let., 13, 63-67.

Çağlar, M., Deniz, E., \& Kazımoğlu, S. (2020). Neighborhoods of certain classes of analytic functions defined by normalized function $a z^{2} J_{\vartheta}^{\prime \prime}(z)+b z J_{\vartheta}^{\prime}(z)+c J_{\vartheta}(z)$. Turkish Journal of Science, 5 (3), 226-232.

Çağlar, M., Orhan, M. (2017). On neighborhood and partial sums problem for generalized Sakaguchi type function. Al. I. Cuza Din lasi (S.N) Matematica, LXIII, f.1, 17-28.

Çağlar, M., Orhan, M. (2019). $(\theta, \mu, \tau)$ - Neighborhood for analytic functions involving modified sigmoid function. Commun. Fac. Sci. Univ. Ank. Ser. A1 Math. Stat., 68(2), 2161-2169.

Darwish, H. E., Lashin, A. Y., \& Hassan, B. F. (2015). Neighborhood properties of generalized Bessel function. Global Journal of Science Frontier Research (F), 15(9), 21-26.

Deniz, E., \& Orhan, H. (2010). Some properties of certain subclasses of analytic functions with negative coefficients by using generalized Ruscheweyh derivative operator. Czechoslovak Math. J., 60(135), 699713.

Goodman, A. W. (1957). Univalent functions and nonanalytic curves. Proc. Amer. Math. Soc., 8, 598-601.

Keerthi, B. S., Gangadharan, A., \& Srivastava, H. M. (2008). Neighborhoods of certain subclasses of analytic functions of complex order with negative coefficients. Math. Comput. Model., 47, 271-277.

Miller, K. S., \& Ross, B. (1993). An introduction to the fractional calculus and fractional differential equations. Wiley.

Murugusundaramoorthy, G., \& Srivastava, H. M. (2004). Neighborhoods of certain classes of analytic functions of complex order. J. Inequal. Pure Appl. Math., 5(2), Art. 24. 8 pp. 
Orhan, H. (2007). On neighborhoods of analytic functions de_ned by using hadamard product. Novi Sad J. Math., 37(1), 17-25.

Ruscheweyh, S. (1981). Neighborhoods of univalent functions. Proc. Amer. Math. Soc., 81(4), 521-527.

Silverman, H. (1995). Neighborhoods of a classes of analytic function. Far East J. Math. Sci., 3(2), 175-183.

Srivastava, H. M., \& Bulut, S. (2012). Neighborhood properties of certain classes of multivalently analytic functions associated with the convolution structure. Appl. Math. Comput., 218, 6511-6518. 